\title{
Movimento Pós-Moderno e Cultura: periodizando e discutindo suas fases
}

\section{Postmodern Movement and Culture: dividing in into periods and discussing its phases}

\author{
Rosana Figueiredo Salvi*
}

Resumo

\begin{abstract}
Esta pesquisa procurou estabelecer uma periodização do pensamento pós-moderno a partir da análise das transformações ocorridas dentro do próprio movimento. Assim, três fases fundamentais foram destacadas. A primeira é entendida como aquela responsável pela formação do pensamento pós-moderno especificamente nas áreas de letras, artes e arquitetura. A segunda é aquela fase que envolve ampla difusão, migração e grandes polêmicas sobre este movimento. Por fim, a terceira fase demonstra relativo amadurecimento do movimento pós-moderno, cuja produção cada vez mais acentuada de teorias ocorre em variadas áreas do conhecimento.

Palavras-chave: Movimento pós-moderno; pós-modernismo; periodização; trajetória do movimento; fundamentos; crítica.
\end{abstract}

\begin{abstract}
This research tried to divide into periods the postmodern thought starting from the analysis of transformations, which happened inside the movement itself. So, three fundamental phases were emphasized. The first one is responsible for to formation of the postmodern thought in the area of Languages, Arts and Architecture, specifically. The second one is the phase that involves wide dissemination, migration and great controversies about this movement. Finally, the third phase demonstrates relative maturation of the postmodern movement, whose production of theories take place in several fields of knowledge.
\end{abstract}

Key words: Postmodern Movement; postmodernism; history; course of the movement; fundamentals; criticism.

\footnotetext{
*Docente do Departamento de Geociências da Universidade Estadual de Londrina, PR. salvi@uel.br

${ }^{1}$ Leslie Fiedler, "The new mutants", 1965, A Fiedler reader (1977), (apud HUYSSEN,1991, p.41)
} 


\section{Introdução}

A natureza da crítica elaborada por pensadores contemporâneos e dirigida aos fundamentos modernos traz a base do pensamento pós-moderno, que se estrutura a partir da crise em que são imersos esses fundamentos. Com os questionamentos e a crítica que se abateu sobre o estatuto da razão, da verdade, da ideologia, da história, do progresso e da evolução, ou seja, com a crise dos grandes discursos genéricos (metanarrativas), um movimento cada vez mais crescente de adeptos passa a elaborar diferentes fundamentos e a estabelecer novas diretrizes dentro do mundo contemporâneo. Uma das vertentes derivadas culminou no pós-modernismo.

Para Featherstone (1995, p.25) o termo pós-modernismo foi utilizado pela primeira vez na década de 1930 para indicar uma pequena reação ao modernismo, tendo se popularizado nos anos de 1960, em Nova York, quando foi usado por artistas, literatos e críticos para "designar um movimento para além do alto-modernismo 'esgotado', que era rejeitado por sua institucionalização no museu e na academia."

Este trabalho traz uma idéia de periodização do movimento pós-moderno a partir de sua manifestação nas artes, na literatura, na arquitetura, na filosofia e demais áreas do conhecimento.

Primeiramente serão demonstrados dois movimentos simultâneos que se estruturam durante os anos de 1950, 1960 e 1970. Um deles encontra bases no pós-modernismo das artes e da arquitetura que ocorria nos EUA e na Inglaterra, inicialmente, muito relacionado também com um período de crises. No final dos anos de 1950 e por toda a década de 1960, esse pós-modernismo se estrutura e passa a ser divulgado fora dos limites de suas fronteiras geográficas originais. O outro, caracteristicamente europeu, encontra bases na Teoria Social Crítica e no pensamento estruturalista, vindo a se desenvolver nos meios acadêmicos, ficando aí encerrado pelas décadas de 1950 e 1960.

Na década de 1970, há uma convergência desses dois movimentos que acabam por se entrelaçar defi- nitivamente, originando uma nova etapa em que aparecerão interesses e desafios renovados que serão debatidos por toda a década de 1980, nos Estados Unidos, principalmente nas universidades da costa oeste americana. Na Europa, com a crítica ressentida de Jürgen Habermas ao pós-modernismo, há um retraimento característico encontrando, os europeus, forte resistência quanto ao uso da terminologia, porém as teorias continuam a ser elaboradas a partir de diferentes "rótulos", como é o caso do pós-estruturalismo, pós-marxismo, etc.

A partir dos anos de 1990, os temas do pensamento pós-moderno passam por novas teorizações que resultam em perspectivas de divulgação e ecletismo para o movimento. Tais temas estarão se desenvolvendo em diferentes lugares do mundo, alcançando disciplinas como a comunicação social, a psicologia, a geografia, a educação, a sociologia, a economia, o direito, entre outros.

\section{Periodizando o Movimento Pós-Moderno}

Huyssen (1991) em seu artigo "Mapeando o PósModerno", defende esse movimento como sendo originalmente norte-americano e tendo passado por momentos variados. Embora a visão do autor não seja por nós inteiramente compartilhada, estaremos adotando suas observações na medida em que ajudam a contextualizar a história do pós-modernismo. Como também gostaríamos de salientar, por caracterizar-se como um movimento difuso, o pós-modernismo põe dificuldades para a sua sistematização. Assim, o ponto de partida da estruturação do trabalho é dado tomando como base o artigo desse autor.

\subsection{Opós-modernismo na sua primeira fase (1950/1960)}

Desde meados dos anos de 1950, houve na literatura e nas artes uma "rebelião" contrária ao predomínio do expressionismo abstrato, da música serial e do modernismo literário clássico. À manifestação desses artistas logo aderiram críticos como Susan Sontag, Leslie Fiedler e Ihab Hassan. Suas reivindi- 
cações baseavam-se na defesa de uma nova sensibilidade e no enaltecimento da literatura popular.

Artistas e críticos compartilhavam a visão de uma situação fundamentalmente nova. A pretendida ruptura pós-moderna com o passado era sentida como perda: as pretensões da arte e da literatura em relação às verdades e aos valores humanos pareciam esgotadas e a crença na força constitutiva da imaginação moderna era apenas outra ilusão.

Duas vertentes da cultura pós-moderna dos anos de 1960 são identificadas.

Na primeira, o descontentamento dos pós-modernistas não era dirigido contra o modernismo como tal, mas sobre a imagem austera do "alto modernismo". A crítica não se refere à exaustão da linguagem ou da literatura e sim à exaustão da estética do alto modernismo.

$\mathrm{Na}$ segunda vertente, havia uma tendência em acreditar que os ativistas dos anos de 1960 estavam pondo o modernismo em prática nas ruas. (Daniel Bell ou Lionel Trilling)

É inegável, entretanto, uma cultura de confrontação diversa nas ruas e nas obras de arte e de literatura, que transformou noções herdadas sobre estilo, forma e criatividade, autonomia artística e imaginação.

Lembramos aqui, como exemplo, os happinings e a arte na paisagem (landscape art) idealizada por Christo, divulgados por Featherstone (1995, p.63). Esse artista projetou eventos que incluíam embrulhar uma parte do litoral australiano e pendurar uma imensa cortina num vale do Colorado. Essa foi uma tentativa de antiarte que questiona o objeto da arte permanente, pondo em relevo uma experiência que não pode ser convertida nem em objeto, nem em mercadoria.

Assim, para Huyssen (1991, p.34), a revolta dos anos de 1960, nos EUA, não foi uma rejeição do modernismo por ele mesmo e sim contra certa versão do "modernismo que havia sido domesticada nos anos 50, incorporada pelo consenso liberal-conser- vador da época e transformada em arma de propaganda no arsenal cultural e político da guerra fria anticomunista. O modernismo contra o qual os artistas se rebelaram já não era mais percebido como uma cultura de oposição. Não mais se opunha a uma classe dominante e a sua visão de mundo, nem havia preservado sua pureza programática, livre da contaminação da indústria cultural".

Huyssen (1991), além de apontar características da fase inicial do pós-modernismo e tentar, a partir delas, chamar a atenção para a continuidade do pósmodernismo em relação à tradição internacional do moderno, também estabelece o pós-modernismo norte-americano como movimento único.

Se contrapusermos a visão de Huyssen (1991) à de Bürger (1984), que analisa o movimento pósmoderno na Europa, veremos que os anos de 1960 foram de manifestos da e contra certa vanguarda, além é claro dos manifestos contra uma lógica da comercialização. Assim, o pós-modernismo dos anos de 1960, caracterizou-se por ser um movimento anti e contra o moderno, tendo um caráter vanguardista.

É assim, que na Europa, segundo Bürger (1984), a meta principal da vanguarda (Dadaísmo, surrealismo, vanguarda soviética pós-revolucionária) foi a de minar, atacar e transformar a arte institucional burguesa e sua ideologia de autonomia e não simplesmente mudar os modos de representação artística e literária. Segundo ele, a vanguarda européia consistiu primordialmente em um ataque à colocação da grande arte nas alturas e à sua separação da vida cotidiana, resultante do desenvolvimento do esteticismo do século XIX e de seu repúdio do realismo. Assim, a vanguarda teria tentado reintegrar arte e vida.

Independentemente da originalidade das manifestações americanas ou européias, podemos extrair alguns pontos que nos permitirão caracterizar o movimento pós-moderno na década de 1960.

Em primeiro lugar, o pós-modernismo dos anos de 1960 caracterizou-se por um forte sentido do futuro e de novas fronteiras; de ruptura e de 
descontinuidade; de crise e de conflito de gerações. Fatos históricos como o movimento pelos direitos civis, as revoltas universitárias, o movimento pacifista e a contracultura demonstram que o pós-modernismo dos anos de 1960 foi mais parecido com movimentos europeus de vanguarda, ou pelo menos se deu em torno das vanguardas, tornando-as específicas, mesmo que seus vocabulários de formas e técnicas estéticas não fossem radicalmente novos.

Em segundo lugar, a fase inicial do pós-modernismo envolveu um ataque iconoclástico contra a arte institucional pelo seu caráter de produção, divulgação, distribuição, comercialização e consumo, que definiu a percepção do seu papel na sociedade. O ataque iconoclasta contra instituições culturais e modos tradicionais de representação pressupôs uma sociedade na qual a arte tinha um papel essencial na legitimação da hegemonia. Seu resultado foi o de desmistificar o discurso legitimador dessa grande arte na sociedade européia. Foi este radicalismo da vanguarda histórica, dirigido contra a institucionalização da grande arte como um discurso de hegemonia, que se tornou uma fonte de energia e inspiração para os pós-modernistas dos anos de 1960. Contrariamente à intenção da vanguarda dos anos de 1960, de fundir arte e vida, o modernismo permaneceu preso à noção mais tradicional de obra de arte autônoma, à construção de forma e conteúdo e ao estatuto especializado da estética. A grande arte havia florescido e se institucionalizado na cultura burguesa dos museus, galerias, concertos, discos e livros de bolso dos anos de 1950. O próprio modernismo havia ficado em evidência graças à reprodução em massa e à indústria cultural.

Sob a forma de heppinings, do pop vernáculo, da arte psicodélica, do acid rock, do teatro alternativo e de rua, o pós-modernismo dos anos 60 procurava, a seu modo, recapturar o ethos de antagonismo que havia nutrido a arte moderna em seus estágios iniciais, mas que esta parecia não mais conseguir manter. É evidente que o sucesso da vanguarda $p o p$, fortemente apoiado na publicidade, não só a tornou de imediato lucrativa como a absorveu numa indústria cultural muito mais de- senvolvida do que aquela com a qual a vanguarda histórica européia jamais tivera de se confrontar (HUYSSEN, 1991, p.39).

Em terceiro lugar, muitos dos primeiros defensores do pós-modernismo dos anos de 1960 partilhavam do otimismo tecnológico trazidos pela televisão, pelo vídeo e pelo computador, combinada com uma visão eufórica de uma sociedade pós-industrial.

O entusiasmo pelos meios de comunicação conduziu a uma quarta tendência identificável nos primórdios do pós-modernismo: uma tentativa de valorizar a cultura popular como um desafio aos cânones da grande arte modernista ou tradicional. Essa linha "populista" dos anos de 1960 ganhou impulso no contexto da contracultura, graças ao abandono da tradição crítica norte-americana em relação à moderna cultura de massas.

O encantamento do prefixo "pós" teve um estimulante efeito na época ${ }^{1}$. O pós-moderno sugeria e anunciava a possibilidade de um mundo pós-branco, pós-masculino, pós-humanista, pós-puritano, etc. A proposta de se preencher o intervalo entre a grande arte e a cultura de massas, bem como a crítica política com base no "eurocentrismo" e no "logocentrismo", podem ser vistas como um marco importante para os subseqüentes desenvolvimentos do pós-modernismo.

Uma das principais diferenças entre o alto modernismo e a arte e a literatura que se seguiram nos anos de 1970 e de 1980, consiste numa relação nova e criativa entre a grande arte e certas formas de cultura de massas.

Somente nos anos de 1970 o termo pós-modernismo começa a ser utilizado. Boa parte da linguagem usada para falar de arte, arquitetura e literatura, nos anos de 1960, ainda provém da retórica do vanguardismo e da ideologia da modernização.

Contra o codificado alto modernismo das décadas precedentes, o pós-modernismo dos anos 60 tentou revitalizar a herança da vanguarda européia e dar-lhe uma forma norte-americana ao longo do que pode ser resumidamente chamado de eixo 
Duchamp - Cage - Warhol. Na década de 70, esse pós-modernismo vanguardista dos anos 60 havia esgotado seu potencial, embora algumas de suas manifestações tenham sobrevivido na nova década. O que havia de novo nos anos 70 era, de um lado, a emergência de uma cultura do ecletismo, um pós-modernismo amplamente afirmativo que abandonara qualquer reivindicação de crítica, transgressão ou negação; e por outro lado, um pós-modernismo alternativo em que resistência, crítica e negação do status quo foram redefinidos em termos não-vanguardistas e não-modernistas, que se adequavam mais efetivamente aos avanços políticos da cultura contemporânea do que as antigas teorias do modernismo. (HUYSSEN, 1991, p.31)

\subsection{Opós-modernismo na sua segunda fase (1970/1980)}

Os avanços culturais dos anos de 1970 são suficientemente diferentes para merecer um tratamento em separado. É no final desse período que se pode falar de uma cultura genuinamente pós-moderna e pós-vanguardista, notando, porém, que o elemento crítico e de oposição na noção de pós-modernismo só pode vir a ser completamente compreendido se considerarmos o fim dos anos de 1950 como ponto de partida para a história do movimento pós-moderno. Se focalizássemos somente os anos de 1970 seria difícil determinar o momento de oposição do pósmoderno, em função da mudança da trajetória do pósmodernismo que ocorre entre os anos de 1960 e de 1970. Seria também difícil perceber o caráter crítico esquerdista implícito nesse movimento.

Em meados da década de 1970, certas premissas básicas da década anterior haviam desaparecido ou haviam pelo menos sido transformadas. A crítica iconoclasta das vanguardas havia exaurido em função de que essas vanguardas estavam já integradas à circulação comercial, o que vem priválas de seu estatuto vanguardista. Também o anterior otimismo diante da tecnologia, do mass media e da cultura popular havia sido substituído por avaliações mais críticas.

A confiança e a exuberância dos anos de 1960 não se manteve diante dos fatos históricos dessa dé- cada. A isso, somam-se freqüentes denúncias com que eram tomados os movimentos da contracultura, da Nova Esquerda e dos pacifistas. O cenário cultural emergente parecia, assim, amorfo e disperso com relação ao dos anos de 1960 .

Poder-se-ia dizer que a batalha contra as pressões normativas do alto modernismo, travada durante os anos 60, havia sido bem sucedida; bem sucedida até demais, alguém diria. Enquanto os anos 60 ainda podiam ser discutidos nos termos de uma seqüência lógica de estilos ( $p o p$, op, cinético, minimalista, conceitual) ou em termos igualmente modernistas de arte versus antiarte ou não-arte, nos anos 70 estas distinções foram perdendo terreno. (HUYSSEN, 1991, p.43).

Nos anos de 1970, a situação das práticas artísticas caracteriza-se pela dispersão e disseminação de idéias, a partir da queda do movimento modernista, e pela superação do mesmo com imagens e temas escolhidos aleatoriamente principalmente na cultura popular contemporânea.

É preciso dizer que nessa década os estilos modernistas não foram abolidos, mas acabaram por se disseminarem na cultura popular, na publicidade, na programação visual das capas de discos, nos acessórios e produtos domésticos, na ilustração de ficção científica, nas vitrines, etc. Assim, o que caracteriza fundamentalmente esse período é que a grande divisão entre o alto modernismo e as culturas populares já não parece relevante no cenário das artes e a crítica pós-moderna da década de 1970 segue essa mesma tendência.

Uma vez perdida essa fronteira entre formas superiores e inferiores de arte e cultura e entre modernismo e cultura popular, as confrontações puderam ser reconsideradas em termos menos reificados. Foi por isso que somente nos anos de 1970 os artistas começaram a se aproximar de formas e gêneros populares e da cultura de massas. Também é nessa década que a cultura popular passa a ser reconhecida e analisada por críticos que começam a se libertar do dogma modernista de que a cultura de massas é pobre e de mal gosto, psicologicamente regressiva e 
destruidora de inteligências.

A possibilidade de misturar e acoplar cultura popular e modernismo pareceu promissora e produziu bem sucedidos trabalhos de arte e literatura nos anos de 1970 .

Foram especialmente as artes plásticas, a literatura, o cinema e a crítica produzidos por mulheres e artistas de minorias, com sua recuperação de tradições enterradas e mutiladas, sua ênfase na exploração, em produções ou experiências estéticas, de formas de subjetividade baseadas em gênero ou raça e sua recusa a ater-se a padrões canonizados que acrescentaram uma dimensão totalmente nova à crítica do alto modernismo e à emergência de formas alternativas de cultura (HUYSSEN, 1991, p.46).

A produção elaborada por minorias possivelmente sobressai à luz da influência de idéias pós-estruturalistas, em especial a de logocentrismo e desconstrução, que continuam sendo difundidas nesse período. Também, nessa década, a participação efetiva das mulheres em todas as atividades produtivas não pode mais ser contida. Assim, passam a ter destaque as produções femininas e o movimento feminista.

A crítica produzida por mulheres lança, por exemplo, uma luz nova sobre o próprio cânone modernista, a partir de uma variedade de perspectivas feministas. Assim, a arte, literatura e a crítica das mulheres são parte importante da cultura pós-moderna das décadas de 1970 e 1980 e mesmo uma medida da vitalidade e energia dessa cultura.

Também é importante ressaltar que a crítica feita ao pós-modernismo dos anos de 1970 dirigiu-se a uma avaliação relativa à perda de qualidade, dissolução da imaginação, declínio de padrões e valores e triunfo do niilismo.

Os anos de 1980 iriam se destacar, por sua vez, por duas grandes investidas que causariam a redefinição da trajetória do movimento pós-moderno. A primeira delas diz respeito ao trabalho publicado na forma de um relatório por Jean-François Lyotard (1986), que expõe "O Pós-Moderno" como condição do conhecimento nas sociedades mais desenvolvidas e o coloca no contexto da crise das narrativas.

A segunda se refere à crítica de Jürgen Habermas (1990), que identifica o movimento pós-moderno com várias formas de conservadorismo e cuja repercussão acaba por causar um retardamento na decisão das esquerdas de levar a sério essa questão ao invés de somente ridicularizá-la. Suas interrogações eram: como o pós-modernismo se relaciona com o modernismo? Como conservadorismo político, ecletismo ou pluralismo cultural, tradição, modernidade e antimodernidade se inter-relacionam na cultura ocidental contemporânea? Em que medida a formação cultural e social dos anos de 1970 pode ser caracterizada como pós-moderna? Em que medida o pós-modernismo se revolta contra a Razão e o Iluminismo e em que ponto tal revolta torna-se reacionária? A investida de Jürgen Habermas contra a visão francesa pós-estruturalista, qualificando-a de antimoderna ou pós-moderna, aproximou os debates que se davam, até então, em níveis diferenciados.

Afirmando uma trajetória do pós-modernismo, concordamos que houve muita confusão nessa época, pois o pós-modernismo enfatizou uma postura estética e artística no campo das artes, arquitetura e literatura principalmente e foi, no entanto, avaliado por inúmeras áreas, como a política e a filosófica, por exemplo. A conseqüência dessa avaliação acabou permitindo uma generalizada confusão de códigos, termos e interpretações que acarretou o desmerecimento para com a real importância desses acontecimentos e dificultou a sistematização dos fatos que se vinham acumulando.

Assim, podemos concluir que o pós-modernismo dos anos de 1970 e 1980 caracteriza-se pelo esmaecimento de seu teor de rompimento, pela sobrepujança dos trabalhos das mulheres e das minorias culturais e pelo extrapolar da questão pósmoderna, que até então se limitava a um comportamento estético e a uma questão de estilo, para áreas mais amplas do conhecimento. 
Nos anos de 1980, o pós-modernismo passa a ser uma questão de política e de cultura num sentido amplo. Mas o que podemos marcadamente ver como uma característica comum do pós-modernismo dos anos de 1960 com o dos anos de 1970 e 1980, é que ambos rejeitam ou criticam determinados aspectos do modernismo, dependendo da área a que se volta o interesse da crítica ou repúdio pós-moderno. Nas artes temos, por exemplo, o alto modernismo rejeitado; na filosofia e na política, os "grandes discursos teóricos" são questionados, passando os seus conceitos por intensas revisões.

No início dos anos de 1980, portanto, o par modernismo/pós-modernismo nas artes e o par modernidade/pós-modernidade, na teoria social, já se tinham transformado em um dos mais disputados campos da vida intelectual das sociedades ocidentais. Entre os anos de 1970 e 1980, a arquitetura, as artes visuais e cênicas e a música, fizeram amplo uso do termo, junto a um forte intercâmbio com a Europa, quando a explicação das teorias do pósmodernismo artístico passou a incluir discussões mais amplas sobre a pós-modernidade. Sobressaíram-se os teóricos como Daniel Bell, Julia Kristeva, Jean-François Lyotard, Vattimo, Jacques Derrida, Gilles Deleuze, Michel Foucault, Jürgen Habermas, Jean Baudrillard e Fredric Jameson.

\subsection{O pós-modernismo na sua terceira fase (1990/ 2000) e o surgimento da pós-modernidade}

Um aspecto introdutório necessário está no resultado da repercussão, nesse período, da obra de Fredric Jameson (1996) que proporcionará uma guinada no direcionamento dos debates que até então vinham ocorrendo.

O período de 1960 caracterizou-se pelo rompimento do pós-modernismo com as práticas estéticas do alto modernismo. Em 1970 e 1980, esse movimento extrapola o campo das artes, arquitetura e literatura, chegando à área da filosofia e política mais com um caráter predominante de avaliação. Isso se dá, principalmente em função da crítica de Habermas ao pós-modernismo divulgado por Jean-Fraçois Lyotard e pelos pós-estruturalistas franceses. Uma das conseqüências mais evidentes desse período é a confusão de termos e códigos que acaba por se estabelecer.

Em 1984, Fredric Jameson lançará sua proposta no âmbito de uma grande narrativa - o marxismo - e buscará estabelecer a diferença entre o moderno e o pós-moderno à luz da concepção de uma norma hegemônica ou de uma lógica cultural dominante. Esse caminho é importante porque a teorização pósmoderna passou a ser elaborada na perspectiva de um campo de forças, no qual diferentes tipos de impulsos culturais tentam se impor. Assim, a idéia de uma dominante cultural como uma nova norma sistêmica e de reprodução, ligada à mudança fundamental na esfera do capitalismo tardio, virá a redefinir os rumos do debate pós-moderno.

A obra de Jameson (1996) alcançou ampla abrangência tendo excelente aceitação. Também possibilitou uma mudança de enfoque sobre essa problemática. Com a chegada dos anos de 1990, ocorre um engajamento de diferentes áreas, cuja aceitação de temas e conceitos derivados do movimento pósmoderno parece ser irreversível, entre as quais participam a geografia, a sociologia, a educação, o direito, o jornalismo e a publicidade e que porão em evidência o caráter de uma nova conjuntura. Nesses anos, concepções já metamorfoseadas pelas produções precedentes aparecem, bem como se dá a sugestão do abandono de temas que viriam então se enfraquecendo.

Somam-se à obra de Jameson, as obras de David Harvey (1992), que trouxe o debate para níveis também mais amplos, discutindo a lógica da pósmodernidade no âmbito da produção econômica e geográfica, a de Mike Featherstone (1995) que não rejeitando a idéia de pós-modernidade, propõe o questionamento sobre a possibilidade da elaboração de pesquisas de cunho sociológico a partir de teorias pós-modernas, tal como se apresentam apontando, neste campo, para a necessidade das grandes narra- 
tivas, e de outros que contribuíram para o alargamento do movimento pós-moderno.

Pode-se considerar que os anos de 1990 encerraram definitivamente a aceitação do movimento pósmoderno como um movimento maduro, que produz seu próprio corpo de teoria com tendência à ampla expansão. Temas indicativos podem ser citados como a análise da sociedade em redes; o teor renovado da noção de identidade; a análise dos novos papéis do trabalho; e as recentes visões sobre o espaço-tempo social. Este é um período, portanto, em que novas teorias são apresentadas para debate, vindas das mais diversas áreas do conhecimento.

Para compreender essa etapa do pensamento pósmoderno como uma diferencial entre as outras, ou seja, para compreendê-la como sendo a fase que se caracteriza pelo grande abandono do debate concentrado na visão rival entre o par modernismo/pósmodernismo e pela definitiva aceitação do movimento pós-moderno como um movimento maduro, fazse necessária uma breve alusão à análise de Fredric Jameson (1996) e uma rápida exposição das propostas que se seguiram.

\section{A obra de Fredric Jameson}

O marxismo, desde o "Manifesto do Partido Comunista" (1848), se posicionou como crítico e defensor, ao mesmo tempo, da modernidade. A própria determinação do caráter contraditório da modernidade tornou-se uma de suas marcas distintivas, ou seja, a combinação de aspectos positivos, como a urbanização e a industrialização, com traços negativos, a exploração, a reificação.

Essa associação fez com que o marxismo rejeitasse as recorrentes tentativas teóricas de caracterizar o mundo atual como uma superação do capitalismo, desde "A sociedade pós-industrial" de Daniel Bell ao "Fim da História" de Fukuyama. O mesmo sucedeu-se com o conceito de pós-modernismo.

Jameson (1996) foi o primeiro teórico marxista que fez uma tentativa de resgatar uma espécie de dialética da pós-modernidade. Entendendo a irrecusabilidade do termo, não só pelas contingências intelectuais norte-americanas, mas por que permite uma descrição adequada da situação em que a modernização, totalmente implantada, não se defronta mais com obstáculos a serem superados, Jameson (1996) procurou analisar a realidade desse novo mundo que designa, segundo ele, por oposição à "modernização incompleta" da modernidade, uma versão mais pura do capitalismo clássico, ou melhor, um terceiro estágio, o capitalismo multinacional, sucessor do capitalismo monopolista e do primeiro capitalismo de mercado.

A nova divisão internacional do trabalho, a dinâmica das transações bancárias, as novas formas de inter-relacionamento das mídias, tudo o que podemos chamar como os sintomas da globalização, seriam, para Jameson (1996), manifestações visíveis do capitalismo tardio. Para estabelecer a topografia deste mundo no qual tudo é moderno por definição, ele tomou a determinação da lógica específica da cultura pós-moderna.

Seu primeiro passo consistiu, pois, na identificação dos traços recorrentes na produção - e nas teorias explicativas - do período que se estende desde a institucionalização acadêmica do modernismo, em meados dos anos de 1960, até os nossos dias. Esses se caracterizam pela "canibalização aleatória dos estilos do passado com a predominância estilística de pastiches"; pela criação de um "hiperespaço" muito além da capacidade humana de se localizar, pela percepção ou mesmo pela cognição, no meio circundante; pela transferência da ênfase do objeto para a representação; etc.

Jameson (1996) estendeu as características das linguagens culturais à esfera da vida cotidiana, à esfera de nossas experiências psíquicas, passando, pois, pelo mapeamento intelectual de uma multiplicidade de áreas do saber ou da arte, dando exemplos dessa nova sensibilidade, procurando conciliar análise formal e histórica. Examinou desde teorias como a de Lyotard (1986), como também discutiu as edificações 
e os conceitos na arquitetura; livros do Nouveau Roman e filmes que quebram a rotina moderna, onde ele demonstrou o estilo pós-moderno.

Desse itinerário, depreende-se que o esmaecimento do sentido histórico, a substituição da categoria "tempo", enquanto dominante pelo "espaço", ou a transmutação das coisas em imagens no processo de reificação, mais do que características de uma dominante cultural constituem traços estruturais do capitalismo tardio.

O estabelecimento de conexões, a descoberta de afinidades entre fenômenos e esferas aparentemente distintas e autônomas, legitima-se como um procedimento do pós-modernismo de Jameson (1996), pela dissolução explosiva da autonomia da esfera cultural, descrita como uma "prodigiosa expansão da cultura". Assim, deve ser considerado como cultural desde o valor econômico e o poder do Estado, até a estrutura da psique.

O eixo comum que une os seus oito ensaios é a busca das condições históricas de emergência de um sistema cultural centrado na visualidade. Essa seria a característica mais singular e preponderante do nosso tempo, tendo no cinema o mais importante elemento de constituição tanto de seu repertório de imagens, quanto de seus processos de interação com o imaginário social.

São essas condições que propiciariam a germinação da "libido escóptica", ou seja, o desejo fixado na superfície visível da imagem, desinvestido de qualquer substância ou profundidade do real. O visual seria essencialmente pornográfico, isto é, sua finalidade seria a fascinação irracional, o arrebatamento. Essa sexualização da imagem deslizou facilmente graças às manobras publicitárias para a sexualização dos objetos, desencadeando a mercantilização universal das coisas e dos seres, num processo geral de reificação do mundo pela sua capa visível.

Afirmou-se, pois, que tudo na sociedade de consumo assumiu uma dimensão estética. Essa teria sido a constatação, análise e a avaliação do estatuto da
"Era da Imagem". O objetivo de Jameson (1996) foi o de transcender esse momento, observando práticas políticas que suscitassem a crítica e a transformação desse contexto, partindo das suas próprias condições de operação e reprodução. Assim, ele reviu tanto as formulações de Brecht e de Benjamim, no sentido de sua expectativa de que as novas tecnologias de comunicação trouxessem um potencial emancipador intrínseco, quanto às análises de Adorno e Horkheimer, fundamentadas no poder corrosivo e transformador das vanguardas modernistas. As condições do presente, a hegemonia implantada de uma cultura popular de massa, obrigariam a requalificar ambas as tradições críticas.

Considerou-se também que nos dias atuais tudo foi mediado pela cultura, até o ponto em que mesmo os níveis político e ideológico deveriam ser desemaranhados de seu modo primário de representação, que é cultural.

Se tudo é cultura e a cultura são "redes de imagens", Jameson (1996) entendeu a crítica cultural como a prática política por excelência e o ato de enfrentar a dimensão mítica da imagem como sua estratégia mais contundente. Sua hipótese central foi a de que as obras de cultura popular não poderiam ser manipuladas, a menos que se oferecesse algum conteúdo. É dessa substância que a cultura de massa teria que se nutrir ao pretender obter algum impacto social significativo.

Quatro pontos têm sido contestados na obra de Jameson (1996):

a) O pós-modernismo implica o esmaecimento da antiga distinção entre alta cultura e cultura de massa;

b) Todas as teorias do pós-modernismo acarretam uma postura política a respeito do capitalismo multinacional;

c) A melhor maneira de usar o pós-modernismo é como um conceito periodizante, apesar dos problemas teóricos do emprego desse tipo de categoria (medida que permitiu que se usasse a noção de lógica cultural dominante); 
d) O pós-moderno exibe quatro características básicas: nova falta de profundidade da teoria contemporânea e da imagem ou simulacro; senso histórico enfraquecido - público e particular, evidente na estrutura esquizofrênica das artes seculares; nova tonalidade emocional, que ele denomina de "intensidades", que substitui os modos (edipianos) anteriores de se relacionar com os objetos; centralidade das novas tecnologias, que por sua vez, estão vinculadas a um novo sistema econômico mundial.

Jameson (1996) forneceu numerosos exemplos dessas quatro características principais, provocando debates tanto nos círculos marxistas quanto em termos mais amplos.

\section{Avaliando o impacto da produção dos anos de 1990/2000}

A receptividade característica da obra de Fredric Jameson possibilitou e inspirou novas propostas analíticas as quais passamos agora a comentar, incluindo um repasse desta repercussão em alguns artigos publicados no Brasil.

Featherstone (1995) tentou contribuir para o avanço de teorias neste campo, vendo nas teorias pósmodernas o mérito de apontarem para mudanças na ordem social, as quais precisariam ser consideradas. Isso preconizou, no âmbito das Ciências Sociais, uma sociologia da pós-modernidade, que apontou para mudanças na cultura contemporânea.

Baseado em Bordieu, Featherstone (1995) classificou tais mudanças a partir de três enfoques: as mudanças nos campos artístico, intelectual e acadêmico; as mudanças na esfera cultural mais ampla, envolvendo os modos de produção, consumo e circulação de bens, que estariam relacionadas às mudanças no poder e nos grupos sociais e de classe; as mudanças nas práticas e experiências cotidianas de diversos grupos que estariam desenvolvendo novos meios de orientação e novas estruturas de identidade.
O grupo dos "novos intermediários culturais", conceito elaborado por Bordieu (1984) apud Featherstone (1995), seria composto por pessoas que se relacionam às ofertas de bens e serviços. Seriam profissionais do marketing, publicitários, relações públicas, produtores e apresentadores de programas de rádio e televisão, jornalistas, comentaristas em geral, comentaristas de moda e profissionais ligados a atividades de caráter assistencial (assistentes sociais, conselheiros matrimoniais, terapeutas sexuais, especialistas em dietética, em estética, etc.). Seriam também considerados como "novos intelectuais" por "adotam uma atitude de aprendizes diante a vida".

Para Featherstone (1995), a estetização da realidade, dada pelo estímulo dinâmico do mercado, colocou a importância do estilo como procura por modas novas, estéticas novas, sensações e experiências novas. Assim, a noção artística contracultural de que a vida é uma obra de arte, recebeu uma aceitação mais ampla. A preocupação com a estilização da vida sugeriu que as práticas de consumo deveriam ser compreendidas além do valor de troca e dos cálculos racionais. A cultura de consumo pressupôs, desta forma, falar num hedonismo calculista para alguns setores; falar nas operações de efeito estilístico para outros e, também, falar numa "economia das emoções". Sugeriu, ainda, uma "estetização da dimensão funcional". Os que criam, produzem e reproduzem a cultura de consumo, transformam "estilo" em "projeto de vida" e incentivam a manifestação da individualidade num conjunto de bens específicos.

Ainda, em uma época de consumo massificado, as mudanças nas técnicas de produção, a segmentação do mercado e a demanda de consumo para uma série mais ampla de produtos, foram vistas como fatores que possibilitaram maiores oportunidades de escolhas e cuja administração tornou-se, em si, uma forma de arte. Isso se deu não somente para os jovens da geração posterior à década de 1960 , mas cada vez mais também para todos os segmentos sociais. Houve, portanto, uma evidência na adoção de estilos de vida fixos por grupos específicos que 
esteve sendo ultrapassada. Esse movimento aparente em direção a uma cultura pós-moderna baseada numa profusão de informações e proliferação de imagens sugeriu também a irrelevância das divisões sociais como ponto de referência importante.

Assim, essa nova sensibilidade, estilo de vida, cultura de consumo e os novos agentes intermediários seriam algumas das grandes categorias de estudo da pós-modernidade para as ciências da sociedade, expressando ainda as tendências atuais de produção de teorias pós-modernas.

Harvey (1992) e Soja (1993), em 1987, elaboraram as primeiras análises na ciência geográfica que levaram em conta o debate pós-moderno. Comentaremos a proposição de Harvey (1992), discutindo alguns de seus aspectos. Isso por que sua obra acabou por tornar-se base para amplas discussões que envolveram a dimensão espacial.

David Harvey (1992) ressaltou a importância das teorias espaciais para a análise pós-moderna, introduzindo o conceito de "compressão do tempo-espaço". Explicitando a experiência do espaço e do tempo, do projeto do Iluminismo, desejou nos fazer ver como inovações nos transportes e nas comunicações, acabaram por "encolher o espaço" numa aldeia de telecomunicações. O tempo veio se reduzindo, por isso, a tal ponto que passamos a assistir apenas ao evento chamado momento, ou seja, apenas o presente passou a existir, pelo menos em alto grau de importância. Esse presente é o tempo do ser esquizofrênico, resultante da pós-modernidade.

Harvey (1992, p.219) demonstrou que a "compressão do tempo-espaço é um desafio, um estímulo, uma tensão e, às vezes, uma profunda perturbação, capaz de provocar, por isso mesmo, uma diversidade de reações sociais, culturais e políticas." O autor advertiu sobre a necessidade que temos de aprender a lidar com esse avassalador sentido de compressão dos nossos mundos, pois existe esta impossibilidade de percebermos as alterações espaço-temporais sem que se tenha uma base, um mundo onde essas mudanças se operacionalizem. Para
Harvey (1992) esse mundo é o mundo moderno e ele o desvelou a partir da análise dos sistemas modernos, tendo como ponto de partida o esquema fordista de produção e a sua acumulação flexível.

Atualmente esta obra é referência obrigatória nos estudos sobre a pós-modernidade.

No Brasil, merecem destaques os temas que se sobressaíram pelo volume da produção. São eles: desencaixe, reencaixe, identidade, multiculturalismo, interdisciplinariedade, direito multicultural e estilo de vida, apontados nos trabalhos de Taschner; Domingues; Pais; Silvério; Pinto; Fernández (1999), entre outros.

Gostaríamos de ressaltar em particular a temática de dois artigos. O primeiro diz respeito à "Velhice e o curso da vida pós-moderno" (DEBERT, 1999). Destacamos neste artigo a ênfase dada à expressão "curso da vida pós-moderna", como um conceito periodizador que delimita as mudanças ocorridas a partir de 1970, com base nos comportamentos. O segundo trata do "Direito pós-moderno" (AZEVEDO, 1999), sendo um artigo que coloca dúvidas sobre a capacidade da razão para obter noções definitivas como as que estão dispostas na forma de Leis. Embasado na afirmação de Minda (1995 apud AZEVEDO, 1999) de que "cada grupo quer a sua lei”, o autor analisou as idéias jurídicas sobre essa questão. Esses dois artigos em particular dão boa noção das possibilidades de tendências que vêm se configurando na cena do debate sobre a pós-modernidade.

Para finalizar o que se verifica então a partir dos anos de 1990, principalmente ao final de sua segunda metade, é que o debate em torno do par modernismo/ pós-modernismo encontra-se já enfraquecido em função da introdução de diferentes interesses trazidos para o debate por varias áreas do conhecimento que não aquelas tradicionalmente inseridas como é o caso das artes, filosofia e política. Assim, o pós-modernismo passa a ser em grande parte compreendido como conseqüência de uma fase histórica maior inserida na opção pelo termo pós-modernidade. É nesse contexto que novas temáticas serão introduzidas. 


\section{Considerações finais}

Diz-se que o mundo pós-moderno é o mundo da cultura e da comunicação, onde se destacam as sociedades de massa urbana e industrial. Isso determina uma sociedade e uma cultura complexas, baseadas na comunicação, no consumo e nos seus tipos de organização.

Aquilo que se refere ao universo do caráter pósmoderno, freqüentemente veio relacionado com a "atenuamento ou extinção ou repúdio ideológico ou estético" do movimento moderno. Assim, o pósmodernismo e a pós-modernidade puderam ser vistos como mudança e ruptura ou na produção estética, ou nas formas de vida atuais.

Considerarmos as maneiras observáveis de comportamento diante desta questão faz-se importante, por que tal caráter de atenuamento ou repúdio gerou polêmicas e embates raramente vistos. Uma das reações observáveis foi a de resistir às tentativas de considerar seriamente as proposições trazidas pelo movimento pós-moderno. Ao desqualificar suas manifestações, imperou-se o ceticismo havendo, muitas vezes, a ridicularização das manifestações deste movimento.

Outra forma de comportar observável foi louvar o pós-moderno e se entregar à idéia de que nele deu-se o abandono de temas tratados pela modernidade. Uma confusão generalizada de códigos foi trazida, desde a crença de que o pós-moderno é antimoderno e eclético, mas o que se verifica é que ele se apresentou como um retorno à tradição; até a de que é antivanguarda por querer criar uma nova arte, mas vê-se que foi vanguardista na sua apresentação de tendências.

Atualmente, com a vontade de analisar ou identificar lucidamente o potencial crítico dessa questão, estudiosos da temática procuram redefinir as suas possibilidades de análise. Assim, tal questão pode ser discutida como uma condição histórica, por exemplo, ao invés de uma análise que mistura teor estético com opção por um estilo. Essa postura veio contribuir para a divulgação do potencial de crítica embutido no pensamento pós-moderno.
O estudo aqui apresentado não trata de defender ou ir contra o movimento e as manifestações pósmodernas e sim de acreditar na possibilidade e importância de descobrir esse momento crítico e um ponto de partida para explicar o desenvolvimento de grande parte das teorias contemporâneas. Estamos com tal postura acolhendo positivamente o debate $\mathrm{e}$ acreditando na possibilidade de assim tratarmos seriamente seus temas sem perder de vista muitas das suas incoerências e fragilidades.

\section{Referências}

AZEVEDO, A. J de. O direito pós-moderno. Revista USP: Dossiê Pós-modernidade e Multiculturalismo, São Paulo, n.42, p.96-101, jun.-ago., 1999.

BÜRGER, P. Theory of the avantgarde. Minneapolis: University of Minnesota Press, 1984.

DEBERT, G. G. Velhice e o curso da vida pós-modero. Revista USP: Dossiê Pós-modernidade e Multiculturalismo, São Paulo, n.42, p.70-83, jun.-ago., 1999.

DOMINGUES, J. M. Desencaixes, abstrações e identidades. Revista USP: Dossiê Pós-Modernidade e Multiculturalismo, São Paulo, n.42, p.94-107, jun./ago., 1999.

FEATHERSTONE, M. Cultura de consumo e pós-modernismo. São Paulo: Studio Nobel, 1995.

FERNÁNDEZ, R. Multiculturalismo intelectual. Revista USP: Dossiê Pós-modernidade e Multiculturalismo, São Paulo, n.42, p.84-95, jun.-ago., 1999.

HABERMAS, J. O discurso filosófico da modernidade. Lisboa: Publicação Dom Quixote, 1990.

HARVEY, D. Condição pós-moderna. São Paulo: Loyola, 1992.

HUYSSEN, A. Mapeando o Pós-Moderno. In: HOLlANDA, H. B. de (Org.) Pós-modernismo e políti$c a$. Rio de Janeiro: Rocco, 1991.

JAMESON, F. Pós-modernismo: a lógica cultural do capitalismo tardio. São Paulo: Ática, 1996.

LYOTARD, J. F. O pós-moderno. Rio de Janeiro: José Olympio, 1986.

PAIS, J. M. Uma Europa aberta ao multiculturalismo? Atitudes dos jovens perante os imigrantes. Revista USP: Dossiê Pós-Modernidade e Multiculturalismo. São Paulo, n.42, p.34-43, jun./ago., 1999. 
PINTO, C. R. J. A democracia desafiada: presença dos direitos multiculturais. Revista USP: Dossiê PósModernidade e Multiculturalismo, São Paulo, n.42, p5669, jun./ago., 1999.

SILVÉRIO, V. R. O multiculturalismo e o reconhecimento: mito e metáfora. Revista USP: Dossiê PósModernidade e Multiculturalismo, São Paulo, n.42, p.4456, jun./ago., 1999.
SOJA, E. W., Geografias Pós-Modernas: a reafirmação do espaço na teoria social crítica. Rio de Janeiro: Jorge Zahar, 1993.

TASCHNER, G. B. A pós-modernidade e a sociologia. Revista USP: Dossiê Pós-Modernidade e Multiculturalismo. São Paulo, n.42, p.6-19, jun./ago., 1999. 